\section{Bionomics of Hylemyia cinerella Fallen}

A Revrew of literature reveals that no account has been given on the bionomics of this species in Egypt. It is frequently met with during the spring and autumn; and the average person would be likely to take it for a small house-fly. It is a coprophagous species. It breeds in cow-and buffalo-dung and in human excrement, but the former is much preferred by the fly as a breeding medium. Experiments show that horse manure does not attract the female fly for oviposition. This fly was reared from human fæces by Howard ${ }^{1}$. Other coprophagous species of Hylemyia $(H$. longicornis and $H$. strigosa) have been reared from cow- and horse-dung ${ }^{2}$.

The breeding season of $H$. cinerella is the spring (March and April) and the autumn (September). On March 4, 1944, three hundred third-stage larvæ were collected from buffalo-dung exposed in the open. These larvæ were transferred to the laboratory and each was placed in a tube with a small quantity of dung and the tube covered with muslin. The larvæ were left to metamorphose and were kept under observation. A few drops of water were added to the dung whenever it showed signs of becoming dry. It was found that the larvæ took three to four days to change to pupæ, and these were transformed to adults in about seven days. The temperature during metamorphosis was about $25^{\circ} \mathrm{C}$.

Department of Entomology,

Faculty of Science,

Fouad I University, Abbassia, Cairo.

' Howard, L. O., Proc. Wash. Acad. Sci., 2, 583 (1900).

'Séguy, S., "Faune de France, Diptères, Anthomyides", 81 (1923).

\section{Inhibitory Action of Dialkyl Succinic Acid Derivatives on the Growth in vitro of Acid-fast Bacteria}

The elucidation, by Shriner and Adams ${ }^{1}$, of the structures of the well-known leprocidal compounds, chaulmoogric and hydnocarpic acids, and the isolation, by Anderson and his co-workers ${ }^{2}$, of tuberculostearic and phthioic acids, from the lipoid fraction of tubercle and other acid-fast bacilli, has stimulated synthesis of various branched-chain fatty acids by a number of workers. Of the large number of these acids synthesized by Adams et al. ${ }^{3}$, the disubstituted acetic acids containing 16-18 carbon atoms were found to be most active against the leprosy bacillus in vitro. Adams's most active acid against the tubercle bacillus inhibited the growth of the latter in a dilution of $1 / 50,000^{3}$. Robinson and Birch ${ }^{4}$ have synthesized a number of trisubstituted acetic acids having two long-chains and have found these acids to possess marked physiological activity resembling that of phthioic acid, producing cell reactions in animals as well as being strongly inhibitory of the growth of the tubercle bacillus in vitro.

The late Prof. T. J. Nolan suggested to one of us that roccellic acid, a product isolated from the lichen Lecanora sordida, having a branched structure, might be inhibitory of the growth of mycobacteria. This acid is a disubstituted succinic acid having the structure $\alpha$-methyl- $\alpha^{\prime}-n$-dodecyl succinic acid ${ }^{5}$. It proved, however, to be only weakly inhibitory ir vitro against $M y c o$. phlei and Myco. tuberculosis (bovis). This was in agreement with the findings of Adams relative to $\alpha$-butyl- $\alpha^{\prime}$-cyclohexyl ethyl succinic acid. No significant increase in antibacterial activity was noted by us with other dialkylated succinic acds; for example, $\alpha$-methyl- $\alpha^{\prime}-n$-hexadecyl, $\alpha-\alpha^{\prime}-$ di- $n$-heptyl succinic acids.

When, however, a methyl alcoholic solution of the anhydride of any of the above acids is neutralized with dilute alkali, only one equivalent of alkali is taken up and the neutral solution contains a mixture of the isomeric monomethyl esters :

\section{$R$. CH. COOH . CH $\mathrm{COOCH}_{3}$ $R^{\prime} . \stackrel{\mathrm{CH}}{\mathrm{C}} . \mathrm{COOCH}_{3}$ and $R^{\prime} . \stackrel{\mathrm{CH}}{\mathrm{C}}$. COOH}

A solution prepared in this way inhibits the growth of the routine organisms, Myco. phlei, Myco. smegmatis and Myco. Rabinowitz at a dilution of $1 / 20,000-$ $1 / 40,000$ of the monoester for six days (the duration of the experiment) and Myco, tuberculosis (bovis) at a dilution of 1/200,000-1/400,000 for 6-9 weeks when certain succinic anhydrides are used. The employment of other alcohols in the production of the halfesters has shown that on the whole no improvement in antibacterial effectiveness may be looked for in that direction.

The cloaking of one of the-COOH groupings was also effected by preparing mixed monoanilides of the type

$$
\begin{aligned}
& R-\mathrm{CH}-\mathrm{CONH} R^{\prime \prime} \text { and } R-\mathrm{CH}-\mathrm{COOH} \\
& R^{\prime}-\mathrm{CH}-\mathrm{COOH} \quad R^{\prime}-\mathrm{CH}-\mathrm{CONHR}^{\prime \prime}
\end{aligned}
$$

where $R^{\prime \prime} \mathrm{NH}_{2}$ represents a wide variety of aminocompounds, such as $p$-aminobenzene sulphonamide, $p$-aminobenzoic ester, aniline, 2-aminothiazole, etc. The inhibitory action of these compounds is of the same order as that of the half-esters but generally somewhat weaker.

All these active substances are strongly hæmolytic, bringing about the laking of washed human red blood cells in 30 minutes at a dilution of $1 / 50,000$ on the average. Incorporating in the solution one eighth of its volume of human serum reduces the hæmolytic dilution to $1 / 2,000$. Unfortunately, it was found that the antibacterial activity of the solution also was now weakened to a similar extent. Preliminary experiments indicate that the globulin fraction of the serum is responsible for the antagonism. It is generally assumed that an antibacterial substance which is strongly antagonized in vitro by serum or a tissue extract will prove ineffective in vivo. With a pathogen which grows so slowly as Myco. tuberculosis, it may, however, be possible to obtain a concentration of unadsorbed drug sufficient to retard at least the growth of the organism in vivo. As investigated so far, these drugs do not appear to be extremely toxic when injected intramuscularly into guinea pigs. Animal protection experiments are now in progress and the results will be published in due course.

Synthesis of other acids is proceeding, but present indications are that the molecular weight of the acid, or alternatively the total number of carbon atoms in the two substituents, must lie within a definite range to produce maximum tuberculocidal activity in the half-ester. Furthermore, with a definite molecular weight, maximum activity is reached when the two substituents are of equal magnitude.

Thus $\alpha$-ethyl- $\alpha^{\prime}$-dodecyl succinic monomethyl ester inhibits Myco. tuberculosis (bovis) in vitro for six 